\title{
NEW PARADIGM OF TRAINING SPECIALISTS AT RUSSIAN FEDERATION SPORTS UNIVERSITIES
}

\author{
Tamara Viktorovna Mikhaylova
}

\begin{abstract}
Using the example of the Russian State University of Physical Education, Sports, Youth and Tourism (SCOLIPE), we consider the modern concept of training coaches at sports universities of the Russian Federation. The development of the concept of training coaches includes a theoretical and methodological justification for the formation of the social and professional status of a trainer, methodological foundations for substantiating the concept of training coaches in the context of the integrated educational system of sports institutes of the Russian Federation, as well as modeling and implementing a training program for trainers in specialized (specialized universities) of the Russian Federation. The technology of teaching sports and pedagogical disciplines contributes to the formation of professional readiness of students of higher education institutions of physical education, as evidenced by the high percentage of employment of graduates in the profile of teacher and trainer.
\end{abstract}

Key words: university, sport, coach, profession, physical education and sports education, professional status, sports and pedagogical disciplines.

\section{INTRODUCTION}

Last 10 years in modern pedagogical culture, a humanistically oriented scientific and pedagogical direction has been actively developing, which implements in the field of higher sports and pedagogical education ideals of developing the potential of a person with a high level of education, able to independently acquire knowledge, think and act creatively, make decisions in non-standard pedagogical situations, be a professionally competent (Mikhaylova, 2018; Neverkovich, 2013).

A critical understanding of the modern educational process in the field of physical education and sports education shows that there are still significant shortcomings of the previous (and so far present) education system, the characteristic features of which are the mono-subjectivity of revealing the features of future professional activity, the dominance of illustrative and explanatory material in training, the lack of a holistic representations of the structure of future professional activity. Excessive saturation with biomedical disciplines and overloading with ideological socio-philosophical-pseudo-economic subjects, educational material that is not interconnected with other subject disciplines with other subject disciplines, does not provide a targeted focus on the formation of a stable, growing professional competence, should be replaced with a new educational space in the context of integrated educational systems of sports institutes of the Russian Federation (Vilensky, 2005; Katrovsky, 2015;
Chichikin, 1995). The success of training highly qualified trainers in sports institutes of the Russian Federation is the result of the joint work of teachers, trainers and athletes, which is determined by the level of mastery of professional competencies. (Guba, 2012; Mikhaylova, 2017). In this regard, there is a need to improve the process of training sports and teaching staff in accordance with development trends of Russian education, which contributes to the provision of both managerial and pedagogical and impacts based on "feedback" between the subject and the object, the creation of subject-subject relations in the pedagogical industry (Mikhaylova, 2016, 2018).

The purpose of research - to substantiate a new paradigm of training specialists at Russian Federation sports universities.

\section{RESULTS AND DISCUSSION}

An analysis of the educational process aimed at training specialists in physical education educational institutions of Russia:

- the social order of modern society for the training of qualified trainers and the lack of common views in conceptual approaches to the training of specialists in Russian universities;

- the need for qualified trainers of a new type, able to more successfully solve issues of professional activity in the system of "youth, student - semi-professional - professional sport" and the lack of elaboration of the issues of 
effective formation of professional readiness of students of the institute of sports for the work of a trainer;

- improvement of the modern content and technological approach in the field of sports education of universities of the Russian Federation on the formation of professional skills (competencies) and the lack of a unified theory and methodology for the training of trainers in the integrated educational system of the institute of sports;

- the need to develop a typology of professional qualities of trainers and the lack of solutions to these issues in an integrated training system for trainers in sports institutes of the Russian Federation;

- the increasing requirements for mastering the legal foundations of the profession of future trainers and the lack of effective technology for regulating professional and labor relations in sports institutes of the Russian Federation;

- the need to attract promising applicants for admission to the institutes of sports of the Russian Federation, related to the need of the physical education and sports industry for qualified specialists with value-motivational attitudes to professional activity and the existing traditional system of professional career guidance that is far from its standard.

The solution of existing contradictions in the system of higher physical education and sports education is determined by the development of the concept of modern training of trainers in sports institutes of the Russian Federation, including:- theoretical and methodological substantiation of the formation of the social and professional status of a trainer;

- methodological foundations for substantiating the concept of training coaches in the conditions of the integrated educational system of sports institutes of the Russian Federation;

- modeling and implementation of a training program for trainers in specialized (specialized universities) of the Russian Federation.

The methodological foundations of the concept of training coaches in the integrated educational system of sports institutes of the Russian Federation include the search for directions and ways to improve the management of educational activities of coaches in universities of a sports profile, taking into account modern socio-economic conditions and the need for their regulation in the system of „youth-student-student-semi-professional - professional sport".

In this regard, the development of new approaches to the management of social processes in modern socio-economic conditions of the sphere of physical culture and sports is due to a number of circumstances: firstly, the lack of legislative provisions that solve the problems of sports activities and social protection of athletes and coaches; secondly, significant costs for the social protection of athletes, coaches and the development of sports infrastructure; thirdly, the low efficiency of the incentive system for coaches and athletes, causing an increase in social tension and, as a result, insecurity in the future; fourthly, the absence of dependence on the quantity and quality of labor, the level of income of subjects of sports activity, as a result of which labor discipline is reduced, confidence in state and political structures of power is reduced; fifthly, the presence of new qualification requirements for personnel; sixth, a decrease in interest in sports and social activity of subjects of sports activities.

Based on the foregoing, we have identified the leading principles for the training of trainers in sports institutes, revealing the social, educational and professional aspects of its development. We attributed the following to them:

$\checkmark$ hierarchical coaching abilities;

$\checkmark$ unity of career guidance;

$\checkmark$ prolongation;

$\checkmark$ orientation to leading qualities;

$\checkmark$ information support of the trainer-athlete system;

$\checkmark$ reliance on the socio-psychological qualities of the individual.

The identification of the leading principles allowed us to determine the organizational and pedagogical conditions that contribute to the highly effective training of trainers in sports institutes: - differentiation and individualization of education, ensuring the effectiveness of the implementation of state educational standards; - the full use of the potential of sports as a means of achieving its targets and the formation of a common and professional culture; - the unity of the target, motivational, substantial, psychophysical components of the professional readiness of the individual; - the unity of knowledge, skills, beliefs, value orientations manifested in the professional competence of the future coach. 
As a result of the study, we noted that the process of becoming a future professional is accompanied by a change in the value orientation of students both at the beginning of playing sports, and when choosing sports activity as a profession. Interest in sports, in fact, is the central link in the hierarchy of the student's basic personal formations, since the natural need for movements and new impressions, new information, and communication is reflected and expressed here. We have established a leading factor reflecting the motivational orientation (49.5\%), interpreted as a manifestation of potential opportunities in coaching through the power of motivation to achieve success in working with athletes and the team. The second most important factor $(24.7 \%$ contribution) reflects the cognitive-temperamental characteristics of the personality. The third factor ( $12.1 \%$ contribution) is the gender and age characteristics of the person, interpreted as socio-demographic, due to the objective working conditions of trainers in a sports school and their experience. The conclusion is logical: the determining moment, both in the perception of the life situation and in life plans, and in relation to the effectiveness of coaching, is the value attitude to professional activity - work by vocation.

In accordance with this, it can be concluded that the diagnostic value of the analysis of initial motivations in the process of students' professional orientation to mastering coaching activities is of significant diagnostic value. We believe that the effectiveness of a professional career is undoubtedly determined by an individual approach, as well as by the typology that makes it possible to identify areas for professional orientation of promising adolescents according to personality traits that are important for coaching and are not amenable to correction. We attributed to them its formation not only in the ontogenetic plane (physical condition), but also in the social plane. In addition, in our opinion, it is important to combine the individual needs of the student in a motivational, substantive and active plan (his desire to be and remain included in pedagogical activity with a specific meaningful content) with the interests of optimizing the activities of the sports institute as a whole, its development, functioning and management.

As a result of the study, we developed a structural-functional model of trainer readiness formation in the conditions of the integrated educational sys- tem of the Institute of Sports of the Russian Federation, which includes the following components: target, methodological, substantive, procedural and effective. As integrated indicators of readiness for future professional activities of specialists in physical education and sports, we have identified the following: motivation for pedagogical activity and content of needs; the level of general theoretical and applied knowledge about the nature and content of the profession of a coach, the functional responsibilities of future specialists in the field of physical education and sports; the level of formation of skills and abilities to solve pedagogical problems that are completely different in complexity; the degree of internalization of professional and pedagogical values. The general scheme of the trainer's professional readiness assumes the allocation of the following components: special professional knowledge; general and special professional skills; creative experience in the profession; personal qualities of the subject, significant for the future profession.

The stage-by-stage formation of professional knowledge and skills in the conditions of the integrated educational system of the Institute of Sports of the Russian Federation provides for the structural and functional organization of the educational process, where its components are pre-university training for graduates of secondary schools, selection and vocational guidance of applicants, and employment of graduates.

\section{CONCLUSION}

The solution of existing contradictions in the system of higher physical education and sports is caused by the development of the concept of modern training of trainers at the Institute of Sports and Physical Education of Russian State University of Physical Education, Sports, Youth and Tourism (SCOLIPE) has shown its viability and high efficiency. Therefore, it can be argued that the developed concept can be recommended for use in the educational process of sports and pedagogical departments of physical education universities and physical education departments in universities of the Russian Federation.

\section{REFERENCES}

Vilensky, M.Ya., Obraztsov, P.I., Uman, A.I. (2005). Technologies of vocationally oriented education in higher education, Pedagogical Society of Russia, Russia.

Guba, V.P. (2012). Features of the solution of the national 
project in the field of secondary education and upbringing, Bulletin of the Bryansk State University, pp. 57-61.

Katrovsky, A.P., Guba, V.P. (2015). Higher education in Russia - the process of transformation and integration, Vesnik Paleskaga dzyarzhay̆naga universita, Gray Gramadsky and human sciences. pp. 32-40.

Mikhaylova, T.V., Pavlov, E.A., Guba, V.P. (2018). Integration of modern sports education in the countries of the European Union. Theory and practice of physical education, Moscow, pp. 95-98.

Mikhaylova, T.V. (2017). Professional readiness of students of the institute of sports for coaching (methodology and technology), RSUPESY\&T, Moscow.

Mikhaylova, T.V., Epifanov, K.N. (2018). Technology for monitoring the selection of promising applicants to universities in the sports field, Theory and practice of physical education, Moscow, pp. 5.

Mikhaylova, T.V. (2016). The technology of educational activity management in the training of trainers at sports institutes of the Russian Federation, Theory and practice of physical culture, Moscow, pp. 71.

Neverkovich, S.D., Popova, A.A. (2013). The education system in the university of physical education as a social institution, Bulletin of the Adygea State University, Pedagogy and Psychology, pp. 173-178.

Chichikin V.T. (1995). Theoretical foundations of the formation of professional readiness of a specialist in the system of physical education and pedagogical training, Novgorod.

Corresponding author:

Tamara Viktorovna Mikhaylova

Ph.D. in Pedagogics, Professor

105122. Moscow city, Russia Sireneviy bulvar street, 4 , building 1 .,

E-mail: t.v.mikhailova@rgufk.ru 